\title{
LíRICA E CIDADE EM “REFÉNS DA METRÓPOLE”, DE JENYFFER NASCIMENTO
}

\section{LYRIC AND CITY IN “REFÉNS DA METRÓPOLE”, BY JENYFFER NASCIMENTO}

Fernando Reis de Sena ${ }^{\prime}$

DOI: 10.11606/issn.1981-7169.crioula.2017.137258

RESUMO: Analisa-se, a partir do poema "Reféns da metrópole", da coletânea Terra fértil (2014), de Jenyffer Nascimento, a relação entre sujeito lírico e cidade. Argumenta-se que o poema - sem escamotear a solidão, a depressão e a deterioração das identidades individuais e coletivas no tempo presente se desenvolve nas relações entre seres humanos e os meios tecnológicos, revelando a cibercidade, em cujos espaços os sujeitos se (des)encontram e se (des)realizam.

ABSTRACT: The article analyzes, from the poem "Reféns da metrópole", of the collection Terra fértil (2014), by Jenyffer Nascimento, the relationship between lyrical subject and city. It argues that the poem - without hiding the loneliness, depression and deterioration of individual and collective identities in the present tense - develops in relationships among human beings and technological means, exposing the cybercity, in whose spaces disagree and derealize.

PALAVRAS-CHAVE: Jenyffer Nascimento; Lírica e cidade; Não lugar.

KEYWORDS: Jenyffer Nascimento; Lyric and city; Non-place.

1 Mestrando em Letras: Linguagens e Representações pela Universidade Estadual de Santa Cruz, Ilhéus, Bahia. Desenvolve o projeto "A cidade do romance, o romance da cidade: cartografias urbanas em Fiel, de Jessé Andarilho". 
REVISTA CRIOULA N ${ }^{\circ} 20-2^{\circ}$ SEMESTRE/2017

\section{INTRODUÇÃO}

cidade contemporânea é um território de crises, (des) limites e (in)certezas que afetam, de forma impactante, o modo de vida dos que habitam ou frequentam seus espaços fragmentados e hierarquizados. Nas últimas décadas, a experiência humana foi desafiada a acompanhar as mudanças arroladas após a Revolução Industrial e a evolução da Informática, quando o espaço urbano apareceu como um lugar privilegiado e a tecnologia pós-moderna passou a fazer, indispensavelmente, parte de nossas vidas.

Essas mudanças, inclusive, transformaram o fazer literário de escritores como Jenyffer Nascimento, cuja produção - ainda tímida, mas de engajamento político-social inquestionável - integra os discursos que subvertem as normas dominantes e tematiza, principalmente, as desigualdades sociais, a memória negra, o feminismo e o amor, compondo "poesias imagéticas que colocam o leitor no meio de um jantar totalmente desconfortável" (SOUZA, 2014, p. 12). Entretanto, em meio a esses temas, é no discurso e em espaços citadinos que a sua obra se centraliza.

Assim, em consonância, destacamos que, para Sandra Jatahy Pesavento, a cidade é um fenômeno que se revela pela "percepção de emoções e sentimentos dados pelo viver urbano e também pela expressão de utopias, de esperanças, de desejos e medos, individuais e coletivos, que esse habitar em proximidade propicia" (2007, p. 14, grifo da autora). Porém, a partir dos anos 1990, a cidade assumiu novas configurações políticas, econômicas e culturais, deixando de ser um locus privilegiado 
para figurar como "um problema e um objeto de reflexão, a partir das representações sociais que produz e que se objetivam em práticas sociais" (PESAVENTO, p. 13).

Essa transmudação da cidade do passado para a globalizada - geograficamente (in)definida e responsável pela rasura das identidades individuais e coletivas - aflorou as descontinuidades, os excessos e a multiplicação dos não lugares, dilacerando o tempo e o sujeito. Daí a deterioração das relações humanas, a desconstrução das instituições e dos conceitos sólidos da modernidade. Marc Augé (2012) diz que os não lugares são espaços incapazes de definir identidade e são caracterizados pelo fluxo intenso de pessoas, as quais não se relacionam e não constituem raízes históricas, mas estabelecem, de alguma maneira, relações com os espaços que frequentam.

Desse modo, os não lugares medeiam "relações consigo e com os outros que só dizem respeito indiretamente a seus fins" (AUGÉ, 2012, p. 87), enquanto os lugares antropológicos se distinguem pelo seu caráter identitário, histórico e relacional, criando um social orgânico, contrário à tensão solitária dos não lugares. Nesse sentido, se os centros comerciais, os aeroportos, o ponto de ônibus, a estação de trem e metrô são considerados não lugares, podemos afirmar que eles se compõem de passagens/deslocamentos do corpo humano por espaços consequentes da atual conjuntura da sociedade de consumo.

Nesta conjuntura social, tempo e espaço são superabundantes e culminam na "supermodernidade", a qual impõe "experiências e vivências de solidão, diretamente ligadas ao sur- 
gimento e à proliferação de não lugares" (AUGÉ, 2012, p. 86). Estes, assim como as cidades, são construções e invenções humanas que criam desestabilidade e ilegibilidade. Contudo, é preciso dizer, ainda, que lugar antropológico e não lugar formam uma matéria fugidia, uma vez que "o primeiro nunca é completamente apagado e o segundo nunca se realiza totalmente" (AUGÉ, 2012, p. 74), isto é, opõem e atraem ao mesmo tempo.

Tendo em vista esses argumentos, o presente estudo, de cunho descritivo-bibliográfico, analisa a relação entre sujeito lírico e a cidade contemporânea. Para tanto, estabelecemos como corpus o poema "Reféns da metrópole", de Jenyffer Nascimento, da coletânea Terra fértil (2014). Consideramos, ainda, o espaço urbano - em especial o da grande cidade, onde a solidão, a depressão e a deterioração das identidades individuais e coletivas se desenvolvem e se realizam - como locus de interesse do poeta contemporâneo, que, sustentado pelas ideias críticas da vida urbana e da sua estrita relação com os espaços por ele representados, caracteriza-se como um poeta cartógrafo, cuja função ultrapassa a de tematizar a cidade para ser a própria cidade, com suas contradições, descrenças, utopias e distopias.

\section{LíRICA E CIDADE}

Um dos conceitos de representação pode ser interpretado como uma possibilidade de "ver o 'objeto ausente' (coisa, conceito ou pessoa), substituindo-o por uma 'imagem' capaz de representá-lo adequadamente" (CHARTIER, 2011, p. 17). 
Essa noção pauta-se na ideia de fidelidade à natureza representada. Entretanto, frente aos caminhos da contemporaneidade, isto parece ser insustentável, visto que, nesse contexto, o imaginário e as subjetividades do representante prevalecem.

Nesse direcionamento, ao representar a cidade real, a literatura cria uma nova, a cidade escrita, traduzida nas linguagens figurativa e alegórica através de um olhar particular, o qual não traz a obrigatoriedade do compromisso de representar fidedignamente o real. Nesse sentido, ao trazer à cena os espaços citadinos e suas múltiplas realidades, a produção literária das últimas décadas fez reacender a discussão entre a dicotomia literatura/ realidade, gerando uma nova problemática em torno da noção de representação e do fazer literário, especialmente, no tocante às representações da urbe contemporânea.

Aleilton Fonseca (2009, p. 61) afirma que as cidades contemporâneas encarnam o mito de Babel, pois "seu usuário e transeunte têm dificuldade de situar-se nelas, de reconhecê-las, mapeá-las e compreendê-las, tal é o emaranhado de signos que compõem a tessitura de seu território físico e simbólico". Nestas cidades - descentradas e babélicas, de sentidos e sujeitos desorientados -, a literatura atua como um discurso de resistência à lógica da ilegibilidade e ao emaranhado de códigos que dificultam sua leitura: uma cidade, ao mesmo tempo, sensível e caótica.

No que tange à poesia contemporânea, Fonseca afirma que:

Os poetas contemporâneos, conscientes e continuadores dessa vertente da poesia ocidental, estendem seu olhar crítico sobre a vida urbana, para transubstanciar em seu texto os feixes de contradições que regem a lógica cotidiana e as relações entre os in- 
divíduos. Nos seus poemas, percebe-se um estado de permanente tensão em face dos valores urbanos e seus diferentes aspectos. Os discursos poéticos transitam entre extremos, de forma dinâmica, pendendo dialeticamente entre a aceitação e a recusa dos valores modernos. Portanto, momentos de crença e de descrença nesses valores se alternam, pessimismo, ironia e entusiasmo dividem espaços ou se chocam nos diversos textos que exprimem a cidade em processo (FONSECA, 2009, p. 61-62).

A poesia urbana surge, desse modo, como resposta à cultura contemporânea, cada vez mais metropolitana, a qual desafia o poeta, na medida em que este a toma como inspiração poética e locus para suas experimentações. Assim, os poetas que exprimem a cidade globalizada buscam a legibilidade do emaranhado de signos que impedem, de algum modo, sua leitura, tornando-a quase indecifrável. Nessa direção:

O poeta aproxima-se e distancia-se metaforicamente da cidade, num movimento de constante recusa e retorno, em tom irônico e afetivo. O poeta está consciente de seu irrecusável estatuto de intérprete da vida urbana, embora sentindo diante dela um mal-estar sem remissão. Angústia e esperança, utopia e realidade constituem forças motivadoras que ele maneja nesse espaço possível da sua experiência de vida e de sua sobrevivência. Assim, os poetas contemporâneos exorcizam a urbe indômita, tentando ler o seu emaranhado de signos (FONSECA, 2009, p. 62). 
O poeta contemporâneo quer essa aproximação para montar uma cartografia de sons e imagens, gritos e silêncios que emanam das metrópoles. Destarte, podemos categorizá-lo de poeta cartógrafo, cuja atuação é de tradutor da cidade real e inomada, procurando e mapeando seus excessos, suas crises e as relações entre indivíduos e seus contextos. Traduzir o que parece ser intraduzível é o desafio deste poeta que, em conjunto com sua poesia, transforma o mundo, uma vez que a atividade poética é "revolucionária por natureza", conforme defende Octavio Paz (1982).

Dessa forma, o poeta cartógrafo assume uma postura revolucionária e política ao tematizar as consequências da globalização a partir de sua escrita libertária, seja para redescobrir os caminhos da urbe movediça, labiríntica e caótica, seja para traçar um tratado cosmogônico que dá origem a uma outra cidade, onde o impossível habita. Entendemos, nesse sentido, que a poesia revoluciona quando seu discurso busca interpretar o mundo, criando uma "abertura ao social", como aponta José Guilherme Merquior (1996).

Ao considerar que "a poesia se rende e se aumenta no esforço de interpretar o mundo, mas esse mundo interpretado é o universo coletivo dos homens, e seus problemas não apenas a afetam - chegam a criá-la" (MERQUIOR, 1996, p. 202), Merquior nos auxilia a argumentar que a poesia contemporânea é uma contemplação do presente, criando e recriando espaços, tanto no campo da materialidade como da virtualidade. O que forma uma escrita fronteiriça por estar dentro-e-fora do espaço social; dentro dos espaços físicos (lugares e não lugares), mas fora de seus limites geométricos, no ciberespaço, por exemplo. Ou seja, fora, mas presa intrinsecamente. 
Portanto, o poeta contemporâneo é cartógrafo porque tem uma visão privilegiada da geografia urbana, além de ser a própria cidade e seus efeitos. Nascido da globalização, da evolução da informática, da proliferação das redes sociais, é responsável por mapear o agora, a matéria poética fundida ao poeta numa condição de dentro-e-fora de sua poesia. Assim, intencionamos analisar justamente essa condição e características do poeta cartógrafo no poema narrativo "Reféns da metrópole", de Jenyffer Nascimento (2014).

\section{JenYfFer NAscimento e a CIDADE CONTMEPORÂNEA}

O poema "Reféns da metrópole" tematiza a São Paulo do presente, de "buzinas, sirenes, faróis [...] tijolo com tijolo, cimento e tráfego" (NASCIMENTO, 2014, p. 42). Uma cidade desumanizada e repleta de não lugares, onde as relações entre humanos e máquinas desintegram o tempo, o espaço e o sujeito. O poema inicia-se com os versos: "Não me espere/ Devo chegar atrasada/ Como tantas outras vezes" (NASCIMENTO, 2014, p. 42), a partir dos quais podemos interpretar como um destaque para a perda da referencialidade, da espacialidade e, sobretudo, da temporalidade - condições que a cidade do presente exerce sobre o modo de vida de seus habitantes.

Em um contexto em que as ações, os pensamentos e a afetividade acontecem tão rapidamente, que mal conseguimos refletir sobre as nossas próprias atitudes, a experiência descrita pelo sujeito lírico encaixa-se no que Zygmunt Bauman (2009) chama de "vida líquida". Assim, referencia uma vida precária e 
de incertezas constantes, na qual o tempo é responsável pelo assombro e pela liquidez do passado, baseada nas efemeridades, nas ilações que o presente contempla, fragmentando e segregando sujeito e espaço.

Os versos chamam a atenção para a imobilidade do sujeito nas cidades globais, as quais são os espaços dos excessos, das multidões desenfreadas, do trânsito parado, mas de tráfego intenso, criando o espaço-caos, onde tudo é aceleração, redução e precariedade, e o ser é bestificado e coisificado. Os versos sugerem, ainda, a ideia de espera, na qual há um alguém inerte, acostumado com a situação, aguardando um outro que se desloca pela cidade e que chegará atrasado "mais uma vez". Assim, os versos criticam, mas também se adequam à realidade temporal e espacial da urbe contemporânea, transformada pelo seu crescimento desolado.

Na estrofe:

Este que insiste em me acordar

Finge controlar o tempo

Mas não passa de um objeto amorfo

Ponteiros em busca de uma identidade.

(NASCIMENTO, 2014, p. 42).

A indefinição do tempo fica evidente porque o despertador/relógio que tem função de registrar e controlar o tempo perdeu sua funcionalidade, tudo é demasiadamente amorfo e confuso. Bauman (2009) afiança que o tempo, na modernidade líquida, muda rapidamente, o que pressupõe o derretimen- 
to dos sólidos e o aumento das pressões sobre os indivíduos inseridos em seus contextos. No discurso poético, percebemos a ambivalência em que a vida na cidade se revela, atraindo e repulsando simultaneamente o sujeito, tornando-a insustentável. Nas estrofes:

\section{O sol adentra a janela \\ Vivaz como nunca \\ Impondo obrigações a alguns \\ Criando possibilidades para outros.}

\section{Buzina, sirenes, faróis}

Compõem a poética da manhã

Nada mais que remeta

Ao baixo meretrício da noite passada.

(NASCIMENTO, p. 42)

O uso dos termos "sol", "manhã" e "noite", além de funcionar como marcadores do tempo, serve como alegorias para representar as incertezas que o sujeito lírico nos envereda desde os primeiros versos. Esses termos nos dizem muito sobre o (re) início da vida e das oportunidades, mas também expõem o marasmo, o pessimismo e as crises que nos rodeiam na contemporaneidade. A cada manhã um novo ciclo se inicia, esquecendo o que foi, virando passado porque o presente é um agora confuso, cheio de (re)inícios, formando um ciclo vicioso em que o sujeito se (des)realiza. Sobre estes reinícios que caracterizam a vida líquido-moderna, Bauman pontua que: 
A vida líquida é uma sucessão de reinícios, e principalmente por isso é que os finais rápidos e indolores, sem os quais reiniciar seria inimaginável, tendem a ser os momentos mais desafiadores e as dores de cabeça mais inquietantes. Entre as artes da vida liquido-moderna e as habilidades necessárias para praticá-las, livrar-se das coisas tem prioridade sobre adquiri-las. (BAUMAN, 2009, p. 08)

Desse modo, "Manhã" e "noite" (des)tecem a vida citadina; o que acontece em um turno, no outro é esquecido ou vira memória, cujas vivências o sujeito lírico não quer lembrar nem ser lembrado delas. Por isso, o "sol" figura como uma abertura ao novo, reconstruindo os caminhos dilacerados e interrompidos pelo próprio tempo, desencadeando uma metáfora que reacende a esperança e aquece os gélidos sentimentos de descrença do presente.

Ao que parece, o sujeito lírico não entende as ações humanas. Ele transita pela cidade, inquieto, mas não desorientado ao estado vagante das pessoas que se movem juntamente com ele. Esse sujeito é blindado ao meio em que transita, como se andasse pelas ruas sem ser percebido, um ser invisível no meio de uma multidão alheia à vida social e presa numa espécie de casulo, onde as pessoas ficam indiferentes ao espaço que ocupam e frequentam, tal como se percebe nos seguintes versos:

Fico a olhar as pessoas no trem

Fones de ouvido e mudez

Por que não cantam? 
Por que não cantam?!

Deve ser porque não escutam

Bezerra da Silva

Deve ser...

(NASCIMENTO, 2014, p. 43).

Podemos, então, notar que o sujeito lírico tenciona buscar as respostas para a condição vagante das pessoas que ocupam o transporte público. Nele, elas são incapazes de fincar raízes e produzir traços identitários porque estão em um não lugar. São indivíduos emudecidos num ato de passividade e alienação frente às questões que circunscrevem a contemporaneidade. Nesses versos, por um lado, o tom cítrico da crítica é agudizado em relação às primeiras estrofes, o discurso confronta o estado de inércia do sujeito, a dependência do uso de dispositivos tecnológicos e aniquilação da rede social humana pela virtual, como efeito da sociedade high tech, de Augé (2012).

Por outro lado, os versos de Jenyffer Nascimento revelam a cibercidade, uma cidade desmaterializada, desterritorializada, imediata, que simula ou tenta substituir a cidade real. Nesse espaço quase sempre associado à negatividade, o mundo incrédulo dá lugar ao mundo reencantado. Nessa perspectiva, Michel Maffesoli (2012) discute que a tecnologia pós-moderna possibilita a busca daquilo submerso e escamoteado pelo tempo, levando-nos à progressividade a partir do ingresso numa sociedade virtual. Esse ingresso culmina numa espécie de "reencantamento do mundo, onde a realidade, tal- 
vez fosse melhor dizer a 'super-realidade', ultrapassa a 'ficção' um pouco mortífera, tediosa e, em vários aspectos, defasada, da teoria racionalista" (MAFFESOLI, 2012, p. 87).

Assim, o que importa é a ligação com o outro e com culturas diversas através da virtualidade dos sites, blogs, chats, uma vez que "o virtual tendo ao mesmo tempo uma eficácia real, permitindo uma forma de gozo real, e elaborando um laço, estabelecendo uma liga, isto é, em sentido pleno, fazendo sociedade" (MAFFESOLI, 2012, p. 87, grifo do autor). Contudo, muitas vezes, ao mesmo tempo em que essa virtualidade aproxima esses outros que estão distantes, ela também distancia daqueles que estão próximos e que, as mais das vezes, se tornam invisíveis - reforçando, assim, a condição de solidão desse "eu" na metrópole.

Então, podemos dizer que os sujeitos representados nos versos de Jenyffer Nascimento: 1- integram uma sociedade desmaterializada, virtual, abstrata e inomada; 2- atravessam as fronteiras geométricas da cidade contemporânea em disputas espaciais; 3- estão conectados a um espaço imaterial, a cibercidade; 4- permanecem dentro-e-fora dessas fronteiras (real e virtual), onde podem ser identificados de qualquer maneira e forjar/assumir várias identidades ao mesmo tempo.

Do mesmo modo, em continuidade, observamos os versos:

Fico a olhar as pessoas nas ruas

Também devem estar atrasadas

Apostam corrida com seres imaginários

Que diariamente as acompanham.

(NASCIMENTO, 2014, p. 43). 
A partir dos versos, notamos a revelação do espaço da cidade contemporânea como um campo de disputas territoriais e temporais, no qual pessoas vagam pelas suas vias, atravessam e cruzam caminhos, freneticamente, em busca de um destino que sempre parece estar distante. A sensação é de que o mundo encolheu, desequilibrando a noção de espaço e, por isso, essa condição de estrangeiro em sua própria origem, uma vez que os sentidos e as identidades deram lugar às efemeridades.

As pessoas não se reconhecem, mas se hostilizam pelo silêncio, são seres reservados e isolados em suas ilhas individuais do presente, com seus problemas, aflições e subjetividades, tomadas pela complexa relação de ser e estar da e na metrópole. Dessa maneira, surgem ações que deflagram a incapacidade de contato com o outro, a inumanidade e a degradação dos laços afetivos que anteriormente eram substanciais para a vida em sociedade e que agora são descartáveis e substituídos pelo uso da tecnologia.

Nesse sentido, Bauman (2009, p. 7) afirma que, na sociedade do presente, "as relações individuais não podem solidificar-se em posses permanentes porque, em um piscar de olhos, os ativos se transformam em passivos, e as capacidades, em incapacidades". Segundo o sociólogo, numa sociedade como a nossa, as tensões se instalam nos temores de "ser pego tirando uma soneca, não conseguir acompanhar a rapidez dos eventos, ficar para trás, deixar passar as datas de vencimento [...]" (2009, p. 7).

Observamos, assim, que essa é a problemática que move os versos de Jenyffer Nascimento - a aceleração da 
vida contemporânea, como ficou registrada nos versos: "Desce do trem./ Sobe as escadas. / Sinal vermelho. / Atravessa fora da faixa. / Corre até o ponto de ônibus. / Motorista passa direto" (NASCIMENTO, 2014, p. 43). Podemos observar que as ações são sucessivas e acontecem em frações de minuto, nada se perde, tudo tem que ser imediato porque não se tem tempo para pensar e agir. Agimos sem perceber os riscos que nos rodeiam, como o acidente por não atravessar na faixa, bem como a perda do ônibus, que, ao que parece, já está atrasado e, por isso, não parou no ponto.

Assim, o poema de Jenyffer Nascimento evoca a incapacidade de controlarmos o tempo a nosso favor porque todas as ações acontecem simultaneamente, o que torna impossível a reflexão sobre as próprias atitudes. No presente, toda a solidez das gerações anteriores foi colocada à prova e questionada e novos dilemas apareceram e afetaram o modo de se relacionar, gerando um (des)conforto no convívio em sociedade. Por isso, finaliza o poema afirmando que "o relógio finge controlar o tempo. / $\mathrm{Na}$ cidade, cada um finge controlar a si mesmo" (NASCIMENTO, 2014, p. 43). Essa assertiva responde a uma questão levantada na segunda estrofe, quando o sujeito lírico busca caracterizar o despertador como algo inútil, sem uma identidade definida, sugerindo que a pós-modernidade tem liquidado a noção de tempo, propondo uma ressignificação de ser-e-estar em tal contexto. 


\section{Algumas Considerações}

Jenyffer Nascimento figura entre os poetas contemporâneos que conseguem tematizar a cidade do presente, observada internamente por um "eu" sempre em trânsito, que se desloca em busca do que foi ou está ameaçado a ser perdido, como o ônibus e o amor do companheiro. Assim, a poetisa confecciona uma cartografia móvel, na medida em que este "eu" textualiza o presente, compondo uma escrita imediatista, sempre atual e transformadora da realidade que tematiza.

O título "Reféns da metrópole" cria uma tensão ao situar o sujeito urbano como dominado, submisso das cidades globais, onde a proliferação dos não lugares incide na criação e recriação das cidades virtuais, tensão esta que rechaça a ideia de espaço e possibilita a compreensão do que a urbe contemporânea se transformou ao longo do tempo. Na São Paulo traduzida pela poetisa, não há o discurso ideologizado de cidade; ela é estridente, ruidosa e calamitosa.

Portanto, a poesia de Jenyffer Nascimento nos permite categorizar o poeta contemporâneo como cartógrafo, cuja condição privilegiada não lhe coloca alheio aos dilemas das cidades globais. Pelo contrário, ele está intrínseco ao contexto, por isso a condição fronteiriça (dentro e fora), ajudando-nos a atravessá-la a partir de sua escrita que exorciza as ilações sobre o tempo presente, revelando-nos os vários reféns que a cidade produz e controla. 


\section{REFERÊNCIAS BIBLIOGRÁFICAS}

AUGÉ, Marc. Não lugares: Introdução a uma antropologia da supermodernidade. Trad. Maria Lúcia Pereira. 9.ed. Campinas, SP: Papirus, 2012.

BAUMAN, Zygmunt. Vida líquida. Trad. Carlos Alberto Medeiros. 2.ed. Rio de Janeiro: Zahar, 2009.

CHARTIER, Roger. Defesa e ilustração da noção de representação. Fronteiras, Dourados, MS, v. 13, n. 24, jul./dez. p. 15-29, 2011. Disponível em: < https://goo.gl/zO6DcB>. Acesso em: 22 out. 2017.

FONSECA, Aleilton. As cidades 'ilegíveis' e a leitura dos poetas contemporâneos. Sitientibus, Feira de Santana, BA, 2009. Disponível em: < https://goo.gl/Uzh64b > Acesso em: 13 jul. 2017

MAFFESOLI, Michel. O tempo retorna: formas elementares da pós-modernidade. Trad. Teresa Dias Carneiro. Rio de Janeiro: Forense Universitária, 2012.

MERQUIOR, José Guilherme. Razão do poema: ensaios de crítica e estética. 2.ed. Rio de Janeiro: Topbooks, 1996.

NASCIMENTO, Jenyffer Silva do. Terra fértil. São Paulo: Ed. do autor. 2014.

PAZ, Octavio. O arco e a lira. Trad. Olga Savary. Rio de Janeiro: Nova Fronteira, 1982, Col. Logos. 
PESAVENTO, Sandra Jatahy. Cidades visíveis, cidades sensíveis, cidades imaginárias. Revista Brasileira de História, São Paulo, 2007. Disponível em:< https://goo.gl/PfrZxm>. Acesso em: 13 jul. 2017.

SOUZA, Elizandra. Terra fértil: escritas cinematográficas de Jenyffer Nascimento. In: NASCIMENTO, Jenyffer Silva do. Terra fértil. São Paulo: Ed. do autor. 2014, p. 11-12.

Submissão: 20/08/0217

Aceite: 29/10/2017 